\title{
VIVER DO LONGE: TRADUÇÃO COMO CORRESPONDÊNCIA
}

\author{
Marcia Sá Cavalcante Schuback
}

Viver longe é viver traduzindo de uma língua para outra, de uma experiência para outra, de uma memória para outra, de um esquecimento para outro e de um silêncio para outro. Viver longe é viver traduzindo de um para outro, pois o longe é nele mesmo a intensa relação de um e outro: longe em relação a um outro lugar e a um outro tempo, longe em relação a um outro, um outro fora ou dentro de nós.

São muitos os modos de viver longe e portanto de traduzir. Pode-se viver longe nostalgicamente, trazendo todo estranho, seja língua, experiência, memória, esquecimento ou silêncio para o já ouvido, já visto e dito. A nostalgia pode ser considerada uma tradução conservadora, uma tradução que obriga o estranho a aproximar-se do já conhecido. Mas também se pode viver longe utopicamente, forçando a língua, a experiência, a memória, o esquecimento ou o silêncio do conhecido a imitar o estranho. A utopia pode ser definida como uma tradução renovadora, uma tradução que obriga o conhecido a aproximar-se do estranho. Esses dois movimentos simétricos de tradução, a nostalgia de trazer o estranho para o conhecido e a utopia de levar o conhecido para o estranho, definem modos bem conhecidos de se viver longe. São modos que buscam superar a distância do longe e o longe das distâncias, trazendo um e outro, o conhecido e o estranho para uma proximidade capaz de establecer uma nova identidade. Viver longe - traduzir nostalgicamente, e viver longe - traduzir - utopicamente é viver sob o imperativo da imitação (que pode ser também chamado de imperativo mimético), operante nos múltiplos e complexos mecanismos de identificação e diferenciação, de unificação e comunitarização que buscam superar o longe das diferenças mediante processos contínuos de aproximação.

Esses modos conhecidos de viver longe - de traduzir - perdem no entanto a sua evidência quando a dor dessa vida se torna aguda, quando a intradutibilidade da experiência se expõe, quando a impossibilidade de se transpor a distância e o longe das 
distâncias torna-se o lugar da vida, o único perto. Nesse instante e lugar - onde o longe é o único perto - não se vive só longe; vive-se do longe. Viver do longe é viver no instante e lugar do poético. Se viver longe é viver traduzindo, poder-se-ia então dizer que viver do longe é viver traduzindo poeticamente.

Se viver longe é condição para se traduzir, se toda tradução expõe sentidos de distância, viver do longe é condição para se traduzir poeticamente e, portanto, para a tradução poética, literária, artística. Teorias românticas e idealistas da tradução elaboradas, por exemplo, por Goethe, Humboldt, Schleiermacher guardam em comum a compreensão de que viver longe é a condição fundamental de toda tradução e de que o desejo de proximidade é a sua disposição fundamental. Goethe considerava que traduzir é levar o conhecido, o "próprio", para o "original”, o estranho, buscando reproduzir no conhecido o estranho. Humboldt considerava que o "original", o estranho, nunca pode ser reproduzido em outra experiência mas que tanto o estranho como o conhecido (o próprio) são expressões de uma experiência arcaica comum a todas diferenças possíveis. Assim, traduzir seria levar o perto e o longe, o conhecido e o desconhecido, o próprio e o estranho para a idéia imemorial de experiência, para o tertius comparationis ou protótipo para imitação. Schleiermacher inseriu nessa discussão a figura do tradutor, argumentando que nele as distâncias se superam, que nele o perto é longe e o longe perto, uma vez que o tradutor é ao mesmo tempo o leitor da experiência do estranho e o autor de uma experiência do próprio, mostrando nele mesmo o ponto em que perto e longe, autor e leitor, estranho e próprio, desconhecido e conhecido se encontram. Nessas teorias românticas, e idealistas, viver longe, traduzir é a busca incansável de trazer o longe para o perto, ou bem afastando-se do perto ou bem procurando o ponto em que perto e longe se encontram e neutralizam numa criação. Walter Benjamin foi um dos primeiros a perceber que o problema da tradução aparece de forma aguda com relação à tradução poético-literária e que, na sua agudeza, traduzir é viver longe não em sentido espacial mas temporal. Ele descobriu uma outra dimensão do viver longe que é viver depois de uma vida prévia. Afinal traduzir é traduzir depois do original e, assim, a partir da irrevogável distância entre presente e passado. Ao discutir a relação entre o "original" e a tradução como questão de "vida continuada" (Fortleben $)^{1}$, da vida que continua depois de vidas anteriormente vividas,

\footnotetext{
${ }^{1}$ Walter Benjamin. "Die Aufgabe des Übersetzers" in Sprache und Geschichte, (Stuttgart: Reclam, 1992), p. 52.
} 
Benjamin entendeu o viver longe não mais como desejo de aproximação mas como necessidade de geração. A idéia de tradução trascriadora dos irmãos Campos pode ser considerada uma expansão da teoria proposta por Benjamin, enunciada como a conjugação de "história e estética", vida nova depois de vidas passadas.

A tradução poético-literária apresenta o problema de como corresponder não apenas ao texto original mas à força criadora do original, sempre única e nesse sentido intransferível e intraduzível. Sendo tradução de um outro, do original, a tradução é sempre e de algum modo repetidora; sendo um novo texto na própria língua, a tradução é sempre e de algum modo, criadora. A tradução faz aparecer em suas várias dimensões uma espécie de entre-vida, pois ela é e não é o mesmo texto, é e não é um outro texto, é e não é uma autoria própria, é e não é o autor alheio. A experiência de entre-vida, radical e aguda na tradução poético-literária, não se deixa explicar através da lógica comparativa de oposições que estrutura em grande parte a vida longe: aqui e lá, próprio e estranho, conhecido e desconhecido, original e imitação, identidade e diferença. Essa lógica vive da ilusão de que o original e a tradução são dois mundos, dois tempos, dois espaços, duas experiências fechadas em si mesmas e, em principio, intransponíveis e de que a tradução seria como um movimento de conquista capaz de superar as muitas distâncias entre duas entidades e identidades. A tradução e, da forma mais aguda, a tradução poético-literária faz aparecer uma outra experiência que é aquela de o original e a tradução se constituirem numa reciprocidade assimétrica. Sendo numa dimensão intraduzível, o original nunca se dá inteiramente, aparecendo como um fragmento, aberto para novos sentidos e fechado na inapreensibilidade de seu sentido total; sendo sempre a partir do original, a tradução nunca se cumpre inteiramente, aparecendo como fragmentária, porque não podendo reproduzir todo o original deixa aberta possibilidades para novas traduções.

A tradução poético-literária não pode ser entendida a partir de uma cartografia de posições, sejam elas espaciais ou temporais (aqui e ali, próprio e estranho, familiar e desconhecido, língua materna e língua estrangeira, antes e depois, primeiro e segundo), porque a sua grafia é uma notação de movimentos. Tradução assim entendida é bem mais uma partitura de verbos: deixar e guardar, partir e chegar, lembrar e esquecer, enviar e receber. Nesse sentido não é propriamente vida longe mas vida do longe. As várias teorias da tradução são teorias surgidas de uma prática textual

\footnotetext{
${ }^{2}$ Campos, Haroldo de. Metalinguagem \& outras metas. $4^{\text {a }}$ ed., São Paulo: Perspectiva, 1992.
} 
e de uma cultura escrita, tendo se desenvolvido com base na realidade fenomenal do texto. $\mathrm{O}$ texto possui em principio uma solidez material que não só permite mas parece obrigar um entendimento da tradução como comunicação entre vasos distintos e distantes, o original e a imitação. Tomando-se porém a tradução em sentido poético e literário de uma vida do longe, traduzir é uma movimentação verbal e não espaciotemporal. Expõe envios e chegadas, esperas e precipitações, demoras e abandonos, memórias e esquecimentos, uma dinâmica que não consegue ser explicada por nenhum tipo de comparação, pois não se trata de aproximar vasos distintos e distantes. Sendo dinâmica verbal, movimentos que não se definem pelo espaço e pelo tempo uma vez que são esses movimentos que definem os espaços e os tempos, a tradução se expõe como correspondência ao que chega e não ao que "é". O original não "é", não "existe". O original chega, como cartas nos chegam ou se perdem. A tradução parte como respostas que se escrevem ou não, que se enviam ou não, que chegam ou não. $O$ texto original chega como carta, pedindo resposta, ou se perde, acolhendo os silêncios dos acasos. Aqui estabelecem-se relações de correspondência e estruturas de comparação.

Cartas, correspondências são experiências literárias que vivem do longe e não apenas o que resulta de um viver longe. Nesse tipo de texto que é a carta, a correspondência, podem-se encontrar elementos para se descrever a experiência da tradução poético-literária como a experiência de tradução que vive do que nunca pode ser superado, vencido, conquistado, ou seja, do longe. E isso de tal modo, que poderíamos aventar uma espécie de equação tradutora, que poderia receber a seguinte formulação: quanto mais intraduzível o original (há inúmeros graus de intradutibilidade, sem dúvida) mais presente o caráter epistolar da tradução. Um exemplo extraordinário dessa experiência é Grande Sertão : Veredas de Guimarães Rosa.

Dois episódios no Grande Sertão nos falam da carta como notação de verbos e não como troca ou comunicação de vasos distintos e distantes. No primeiro, é questão o jeito de contar, a própria definição do contar a "lembrança da vida gente".

A lembrança da vida da gente se guarda em trechos diversos, cada um com seu signo e sentimento, uns com os outros acho que nem não misturam. ${ }^{3}$

\footnotetext{
${ }^{3}$ Grande Sertão : Veredas. Rio de Janeiro: Nova Aguilar. João Guimarães Rosa: Ficção Completa. v.
} 2, p. 132. Todas as passagens de Rosa doravante citadas referem-se a essa edição. 
É um contar diferente, desconjuntado, desalinhavado porque se trata de coisa importante.

Contar seguido, alinhavado, só mesmo sendo as coisas de rasa importância. De cada vivimento que eu real tive, de alegria forte ou pesar, cada vez daquela hoje vejo que eu era como se fosse diferente pessoa. Sucedido desgovernado. Assim eu acho, assim é que eu conto. (p. 132)

Cada "vivimento que eu real tive, de alegria forte ou pesar", conta de uma "diferente pessoa", porque cada "vivimento real" é transformador. Esse conto tem de ser "desgovernado" porque não pode estar submetido a nenhum governo de uma identidade firme e firmada, seja de tempo ou de espaço, seja de sujeito ou de objeto.

O senhor é bondoso de me ouvir. Tem horas antigas que ficaram muito mais perto da gente do que outras, de recente data. O senhor mesmo sabe. (p. 132)

Descrevendo o conto, o contador lembra-se de uma carta que recebera de Nhorinhá, filha de Ana Duzuza.

Mire veja: aquela moça, meretriz, por lindo nome Nhorinhá, filha de Ana Duzuza: um dia eu recebi dela uma carta: carta simples, pedindo notícias e dando lembranças, escrita, acho que, por outra alheia mão. Essa Nhorinhá tinha lenço curto na cabeça, feito crista de anu-branco. Escreveu, mandou a carta. Mas a carta gastou uns oito anos para me chegar; quando eu recebi, eu já estava casado. Carta que se zanzou, para um lado longe e para o outro, nesses sertões, nesses gerais, por tantos bons préstimos, em tantas algibeiras e capangas. Ela tinha botado por fora só: Riobaldo que está com Medeiro $\operatorname{Vaz}$. E veio trazida por tropeiros e viajores, recruzou tudo. Quase não podia mais se ler, de tão suja dobrada, se rasgando. Mesmo tinham enrolado noutro papel, em canudo, com linha preta de carretel. Uns não sabiam mais de quem tinham recebido aquilo. Ultimo, que me veio com ela, quase por engano de acaso, era um homem que, por medo da doença do toque, ia levando seu gado de volta dos gerais para a caatinga, logo que chuva chovida. Eu já estava casado. Gosto de minha mulher, sempre gostei, e hoje mais. Quando conheci de olhos e mãos essa Nhorinhá, gostei dela só o trivial do momento. Quando ela escreveu a carta, ela estava gostando de mim, de certo; e aí já estivesse morando mais longe, magoal, no São Josezinho da Serra - no indo para o Riacho-dasAlmas e vindo do Morro dos Ofícios. Quando recebi a carta, vi que estava gostando dela, de grande amor em lavaredas; mas gostando de todo tempo, até daquele tempo pequeno em que com ela estive, na Aroeirinha, e conheci, concernente amor. Nhorinhá, gosto bom ficado em meus olhos e minha boca. De lá para lá, os oito anos se baldavam. Nem estavam. Senhor subentende o que isso é? A verdade que, em minha memória, mesmo, ela tinha aumentado de ser mais linda. De certo, agora não gostasse mais de mim, quem sabe até tivesse morrido... Eu sei que isto que estou dizendo é dificultoso, muito entrançado. Mas o senhor vai avante. Invejo é a instrução que o senhor tem. Eu queria decifrar as coisas que são importantes. E estou contando não é uma vida de sertanejo, seja se for jagunço, mas a materia vertente. Queria entender do medo e da 
coragem, e da gã que empurra a gente para fazer tantos atos, dar corpo ao suceder. O que induz a gente para más ações estranhas é que a gente está pertinho do que é nosso, por direito, e não sabe, não sabe, não sabe!

Sendo isto. Ao doido, doideiras digo. Mas o senhor é homem sobrevindo, sensato, fiel como papel, o senhor me ouve, pensa e repensa, e rediz, então me ajuda. Assim, é como conto. Antes conto as coisas que formaram passado para mim com mais pertença. Vou the falar. Lhe falo do sertão. Do que não sei. Um grande sertão! Não sei. Ninguém ainda não sabe. Só umas raríssimas pessoas - e só essas poucas veredas, veredazinhas. O que muito lhe agradeço é a sua fineza de atenção.

A carta expõe o texto literário, o conto, como o que chega ao leitor e como movimento de chegada, o texto vem ele mesmo atravessado por inúmeras distâncias, "oito anos", trazendo a transformação da disposição com a qual foi escrito - "Norinhá gostava de mim", "eu gostei dela só do trivial momento", o esmaecimento da simples notícia, do simples gostar, um estranho esmaecimento pois com o amarelar do tempo, das travessias, da circulação dos inúmeros caminhos e descaminos da entrega, o esmaecimento criou também intensificação, a ponto de na hora de receber a carta esquecida, até porque dela nada se sabia, o amor de repente nasceu de novo, crescido, acrescido dos anos de distância, dos anos do não saber. Na carta se "está pertinho do que é nosso por direito e não se sabe, não se sabe, não se sabe!”. Na carta se está perto do longe e longe do perto, como se está longe da própria língua e perto da língua do outro, a língua estranha.

A carta expõe esse perto longe e esse longe perto que dimensiona o não-saber operante em toda tradução. Traduzir como leitor que não sabe tudo da outra língua e nem da própria, traduzir para o leitor que nada sabe ou não sabe tudo, traduzir como modo de saber e narrar, traduzir como contar o ter ouvido, o ter lido uma carta, um texto que vem de muito longe, mesmo que esse longe seja aqui do lado; que passou por inúmeras leituras, mesmo que tenha sido escrito ontem, expondo o original como o que só aparece como original esmaecido, no esmaecimento propiciado pela distância de um estranhamento - essas são as cartas da tradução, do seu jogo. E se a carta expõe a tradução como "um estar perto do que é nosso e não saber..." é porque ela também expõe o saber como um estar longe do que não é nosso. Essa simétrica oposição aparece no texto quando Riobaldo se vê entre Diadorim e Otacília.

- "Riobaldo, eu gostava que você pudesse ter nascido parente meu..." Isso dava para alegria, dava para tristeza. O parente dele? Querer o certo, do incerto, coisa que significava. Parente não é o escolhido - é o demarcado. Mas, por cativa em seu destinozinho de chão, é que árvore abre tantos braços. Diadorim pertencia a sina 
diferente. Eu vim, eu tinha escolhido para o meu amor o amor de Otacília. Otacília quando eu pensava nela, era mesmo como estivesse escrevendo uma carta. Diadorim, esse, o senhor sabe como um rio é bravo? É, toda a vida, de longe a longe, rolando essas braças águas, de outra parte, de outra parte, de fugida, no sertão. E uma vez ele mesmo tinha falado: - "Nós dois, Riobaldo, a gente, você e eu... Por que é que separação é dever tão forte?..." Aquilo de chumbo era". (p.610)

A carta, a necessidade de tradução se impõe desde uma escolha, a escolha do amor de Otacília, do não parente, do que não está demarcado, do estranho. Por isso, quando ele pensava em Otacília, "era como se estivesse escrevendo uma carta". Diadorim que era amor demarcado, que era o próprio de onde se está sempre perto sem saber, não pode ser traduzido, ao menos não da mesma forma, pois dele, do próprio, só se pode partir, como num "rio bravo", pois não partir seria morrer.

Mais adiante, acontece de Riobaldo querer escrever uma carta para Otacília, uma carta muito singela, notícias, saudações, lembranças e quem sabe uns versos também. Mas a carta ficou pela metade, porque "essa sinceridade era dificultosa". A carta era pela metade, pela metade do próprio e do estranho, da escolha e do não escolhido, Otacília e Diadorim, o que se sabe e o que não se sabe, o perto do longe e o longe do perto, sempre pela metade, sempre incompleto, nem lá nem cá porque se é sempre e de novo aqui e ali, próprio e estranho. Assim, traduzir é sempre trazer a si mesmo para o longe do perto e para o perto do longe e nunca para um lugar ou um tempo distinto e marcado vindo de outro também distinto e marcado.

Máximo me lembro é de que, na minguante, se estava no veredal das cabeceiras de um córrego, lugar de desmedidas pastagens, adonde os cavalos usufruírem descanso. A lá esbarramos e paramos, por uns dias. Me lembro, eu quis escrever uma carta.

Essa minha carta, eu podia destacar um homem, dos ligeiros, ele ia levava em mão, à Otacília, minha noiva, trazia a resposta. $\mathrm{O}$ que eu cogitei de escrever era muito singelo: as notícias de minha saúde, pergunta de como era que ela e os parentes iam passando, saudações de lembranças. Admiro que achei natural de não falar coisa de minha glória de chefia, por oras. Por quê? Pois. E tive vontade de traçar uns versos também: mas que a aragem não ajudava a deduzir. Era uma sinceridade muito dificultosa. Escrevi metade.

Isto é: como é que podia saber que era metade, se eu não tinha ainda ela toda pronta, para medir? Ah, viu?! Pois isto eu digo por riso, por graça; mas também para lhe indicar importantefato: que a carta, aquela, eu somente terminei de escrever, e remeti, quase em data dum ano muito depois... Digo o porquê? Próprio porque não pude. Guarde o senhor: não pude completo. Mas, guarde, por outra: o dia vindo depois da noite-esse é o motivo dos passarinhos...

Falo por palavras tortas. Conto minha vida, que não entendi. O senhor é homem muito ladino, de instruída sensatez. Mas não se avexe, não queira chuva em mês de agosto. Já conto, já venho - falar no assunto que o senhor está de mim esperando.

E escute. 
Tinha o Maligno?

Às vezes, penso. Um boneco de capim, vestido com um paletó velho e um chapéu roto, e com os braços de pau abertos em cruz, no arrozal, não é mamolengo? $\mathrm{O}$ passopreto vê e não vem, os passarinhos se piam de distância. Homem, é. O senhor nunca pense em cheio no demo. $\mathrm{O}$ mato é dos porcos-do-mato... O sertão aceita todos os nomes: aqui é o Gerais, lá é o Chapadão, lá acolá é a caatinga. Quem entende a espécie do demo? Ele não fura: rascrava. Demorar comigo ele podia. E, o que não existe de se ver, tem força completa demais, em certas ocasiões. A ele vazio assim, como é que eu ia dizer: - "Te arreda desta minha conversa!"?... Ao que, pois, o que eu ia pondo, na carta, era quase que uma ordenada lembrança, a igualzinha repetição daquilo de Diadorim: que ela rezasse por mim, Otacília, orações rezasse... Ia. Ah, mas, aí, houve. Amoleci mão antes de coração: não pude. Não pude, diabralmente, desarrazoado - por outras fortes ordens... - ; e então de repente tive vergonha, desgostei de estar querendo escrever aquela carta. Desisti, guardei na mochila aquela metade. Um homem é um homem, no que não vê e no que consome. Ah, não. Otacília, eu não merecia. Diadorim era um impossível. Demiti de tudo.

Fazendo a experiência de que o homem é, sem predicamentos, e portanto o que nada possui de distinto e marcado, sendo e não-sendo sempre e de novo, na contundência dessa "sinceridade mutio dificultosa" onde não se pode escapar de que "o homem é um homem no que não vê e no que consome", a única forma de contar, numa carta, numa tradução, se vê fracassada, desgostosa, pois a impossibilidade de dizer o outro e o estranho faz aparecer a dificuldade mais tremenda e abissal, que é a de dizer o próprio, de contar e narrar na própria língua.

Essas referência corrida à carta escrita mas quase perdida e à carta quase escrita e nunca enviada no Grande Sertão, expondo a relação entre o que se escolhe - o longe - e o que nunca se escolhe - o perto - entre o estranho e o próprio, o original e a imitação é apenas um esboço para se desenvolver uma espécie de fenemenologia descritiva do movimento tradutor que segue os os movimentos de partida e chegada, envio e recebimento, espera e demora trançados no ir e vir da carta, da correspondência, ou seja, o de onde vem e para onde vai o conto. A carta, a correspondência expõe esses movimentos de maneira aguda, pois nela se escreve e se lê de modo a considerar cada palavra como o que vem ao encontro e não como um fato lingüístico e, assim, como o que traz consigo a força do inesperado, a força capaz de abalar tudo o que se espera.

No caso da tradução de Guimarães Rosa e do Grande Sertão em particular, essa discussão torna-se ainda mais pertinente considerando-se a correspondência com os tradutores, sobretudo com Edoardo Bizarri e Curt Meyer-Clason, pois aqui a 
correspondência sobre a tradução de uma das obras mais intraduzíveis da literatura moderna apresenta a correspondência como um percurso decisivo de tradução.

Toda tradução criadora é tradução do intraduzível. Mas com relação a Guimarães Rosa estamos diante do problema de se traduzir o mais intraduzível. Estamos diante de uma vida que só pode viver do longe, lançando-se nessa entre-vida, quase morta, quase viva que é essa experiência do limite da linguagem numa linguagem de limites ilimitados. Meyer-Clason exprimiu essa tarefa como a tarefa do espírito (Geist) saltar em horizontes (der Geist in Horizonte ausgreifen). Para definir essa tarefa do espírito cabe descrever os âmbitos da correspondência delineados nessa troca de cartas tradutoras sobre a tradução. Fica a promessa. 